\title{
The domestic practice of the development of science and technology finance and Its Enlightenment to Inner Mongolia
}

\author{
Chu Haiying \\ 1.School of economics, Wuhan University of Technology, Wuhan 430070 \\ 2.School of finance, Inner Mongolia University of Finance and economics, Hohhot, Inner Mongolia \\ 010070
}

Keywords: science and technology finance; science and technology credit; venture capital; science and technology insurance

Abstract. Strengthening the combination of science and technology finance is an important means to implement innovation driven development strategy.Since 2011, the Ministry of science and technology in conjunction with the eight ministries, the Ministry of finance, people's Bank of China and other selected 16 Beijing Zhongguancun, Chengdu hi tech Zone, Shanghai, Wuhan and other areas, to actively promote the combination of technology and finance pilot work, explore the new mechanism of scientific and technological resources and financial resources docking, and made significant progress. This paper attempts to sum up the experience of the pilot areas of scientific and technological financial innovation, in order to provide a good reference for the further development of Inner Mongolia's science and technology finance.

Science and technology finance is an important part of the national science and technology innovation system and the financial system. It is the close combination of the "first productivity" and "the first impetus".In order to realize the strategy of "independent innovation country", in recent years, our country vigorously promote the development of science and technology finance.In October 2011, the Ministry of science and technology, the Ministry of Finance and other eight ministries jointly developed a number of Guiding Opinions on promoting the combination of technology and finance to accelerate the implementation of independent innovation strategy;At the same time, the Ministry of science and technology in conjunction with the "three" joint determination of sixteen regions of Beijing, Zhongguancun Chengdu high tech Zone to carry out pilot technology and financial integration, financial innovation of science and technology ushered in a new opportunity.The pilot areas in the promotion of science and technology in the financial sector, overall planning, system construction, financial services model and product innovation has many new breakthroughs, in the nationwide promotion of technology and Finance Based on the accumulated the rich experience in the demonstration.To conform to the national policy, combined with the autonomous region in the long-term science and technology development plan, Inner Mongolia has actively carried out the combination of technology and finance,After several years of efforts, in the construction of technology financial services system has achieved certain results

First, the domestic pilot areas of scientific and technological financial development experience summary.

(a) Pay attention to the innovation of science and technology financial policy

The development of science and technology financial innovation depends on the regulation and guidance of government policy.In recent years, the pilot areas in under the guidance of the policy document of the national programme, attaches great importance to local policies and regulations of construction and innovation, mainly involved in the field include fiscal guidance (entrepreneurial venture investment fund, angel investment guide fund), risk compensation mechanism construction technology interest payments on loans and credit risk compensation, science and technology insurance subsidies, small and medium enterprises credit guarantee fund, financial institutions, the innovation of the forms of (technology banking or Commercial Bank branch of science and technology, science and technology of small loan companies, financing guarantee institutions), service system (Science and technology management, combination of technology and Finance, financial service platform of science and technology, Regional OTC market) etc.. 
(b) Pay attention to the innovation of science and technology finance development model

As the basis of scientific and technological innovation, the degree of development of financial markets, the layout of the emerging industries and geographical and cultural differences in the environment,Financial development in science and technology could not apply a fixed model, in view of the reality of the situation, many pilot areas have innovation explore apply to local financial and technological development, and achieved good results, provides referential sample for other parts of the country.The following are some of the more typical models:(1) Zhongguancun Beijing model.The research gold cooperation mechanism innovation is the biggest feature, research cooperation mechanism refers to the new industry and universities and research institutions + enterprise $\mathrm{R} \& \mathrm{D}+$ financial institutions,the purpose is through resource integration,to set up all kinds of cooperation alliance, play alliance members each in terms of resource, technology, brand, capital and other advantages innovative mechanisms for cooperation, expand areas of cooperation and ultimately promote the Zhongguancun Science and Technology Park financial services innovation system construction.(2) the development model of Shanghai Zhangjiang hi tech park, a base, a center, a product, five pilot "

(c) Pay attention to the innovation of the financial system of science and technology

Science and technology financial system mainly includes two aspects: the financial system and the market science and technology financial system. The financial system is mainly embodied in the way of financial investment in science and technology innovation, science and technology, science and technology insurance credit compensation and reward subsidies and policy financing guarantee system innovation etc..Market of science and technology innovation in the financial system cover all non public finance of science and technology in the financial sector, including multiple areas of the development of bank credit system innovation, new technology of financial institutions and the multi-level capital market system innovation.System is an important guarantee for the smooth development of science and technology finance, all over the country attaches great importance to the innovation and construction of the financial system of science and technology, innovation and innovation.

(d) Focus on the construction of science and technology financial services center

Throughout the financial services technology center of the organizational structure, functions, business content, operation mechanism from the point of view, the financial service center of science can be summarized for financing, guarantees, insurance, assessment, consulting, legal, finance, training and other functions as one of the integrated service platform.It guides as government funds, the effective integration of all kinds of scientific and technological projects and enterprises, such as all kinds of elements of science and technology and financial capital, financial capital, and other capital elements, innovative financial products and tools, effectively alleviate the investment and financing information asymmetry of contradiction, financing needs of the different stages of the development of small and medium sized enterprises of science and technology, providing a one-stop, personalized financial services, achieve science and technology, the financial resources to gather together sharing and efficient docking.

Two, Inner Mongolia science and technology financial development present situation and problem analysis.

(a) Inner Mongolia science and technology finance development present situation

1. the preliminary establishment of the working mechanism of the combination of science and technology and Finance

With the state of science and technology and the continuous progress of the financial work, the Inner Mongolia science and technology financial work has been launched, the introduction of a number of special policies, and establish a government related departments of the work mechanism.In December 2011, the autonomous region science and technology department in conjunction with the Department of finance, "a line of three Bureau jointly issued" to promote the Inner Mongolia Autonomous Region Science and technology financial work combined with the certain opinions ", put forward the combination of technology and financial goals, main task and specific safeguard measures.Subsequently, the Inner Mongolia Autonomous Region Science and 
Technology Department Cooperation Department of finance, finance office, the insurance regulatory bureau and other departments in the organization of the hi tech Zone of Baotou held "Inner Mongolia Autonomous Region Science and technology and financial binding work will promote", the meeting also issued "on the Baotou Rare Earth hi tech Development Zone included in the autonomous region science and technology and Finance with pilot work of the decision"

2.Inner Mongolia science and technology foundation is in good condition

Science and technology base, the autonomous region to promote scientific and technological innovation, scientific and technological innovation environment continues to optimize. First of all, science and technology investment has increased year by year.2013, Inner Mongolia total R \& D expenditure reached 11 billion 720 million yuan, compared with 2005 growth of 9.02 times; 2013 R\&D investment intensity reached $0.70 \%$, since 2005 , the avera,ge annual growth rate reached 15.73\%.In addition, the local financial investment in science and technology in Inner Mongolia showed an annual growth trend, with an average annual growth rate of 56.66\%, in 2006 the autonomous region of Fiscal Science and technology expenditure for the yuan, in 2013 reached 3.3 yuan, an increase of times.Secondly, improve the consciousness of science and technology, science and technology output increased significantly. In 2013, the region's patent applications 6388, an increase of 3.39 times more than 1455 in 2005; in 2013 to apply for a patent granted in 3836, an increase of 3.54 times more than 845 in 2005.Again, a certain level of integrated technology has been improved.In 2013, the autonomous region comprehensive scientific and technological progress level monitor index of 43.28, ranking eighteenth in the country, up to 4.Fourth, the construction of high technology platform carrier is constantly strengthened. As of the end of 2013, the autonomous region has a state-level high-tech park -- Baotou National Rare Earth hi tech Zone, 2 National Agricultural Science and Technology Park, the cultivation of the three state-level high-tech industrial base, a national industry base of modern service industry and 17 national test demonstration park.Fifth, scientific and technological personnel team build achievements.

2 the level of development of the financial industry in Inner Mongolia has improved steadily

In recent years, Inner Mongolia's financial market structure has continuously improved, the level of financial services has improved significantly, and the financial ecological environment has improved significantly.First, banks basically formed a multi-level, multi function of the organizational structure of the system, as of the end of 2013, Inner Mongolia has policy banks, state-owned commercial banks, joint-stock commercial banks, city commercial banks, postal savings banks and financial institutions in rural areas etc. all kinds of banking institution with legal person status 164, outlets 4675 home.In addition, the banking sector continued to increase the total amount of financial resources, the end of 2013, the region's total amount of RMB deposits and loans were \$, respectively, compared with 2012, respectively, an increase of $11.7 \%$ and $14.7 \%$.Secondly, the capital market financing environment gradually improved, all kinds of enterprises to use the stock market and the bond market, the proportion of direct financing continues to improve. As of the end of 2013, the region a total of 25 domestic listed company, which listed on the main board of the Shanghai and Shenzhen A-share is 20, the SME board listed 2 and 3 GEM listed companies, domestic listed companies A-share stock market value of 3117.13 billion yuan, accounting for 18.52\% of Inner Mongolia GDP, compared with a year earlier growth 4.97\%."Eleventh Five Year" period since the autonomous region has 30 enterprises through the issuance of enterprise bonds, can be convertible bonds, short-term financing coupons, medium-term notes, small and medium-sized enterprises set bonds in the bond market financing, 2012 and 2013 issued corporate bonds scale were up 100.4 billion yuan and 86.8 billion yuan.Again, the insurance market.

(b) the main problems in the development of Inner Mongolia science and Technology Finance

1. bank technology financial resources supply

On the one hand, the total amount of bank credit. Inner Mongolia science and technology financial development practice has proved that bank loans have been the main source of investment in science and technology innovation. Autonomous regions in various types of loans increased year by year, the investment in science and technology credit is also significantly increased.But in all kinds of commercial bank loans, the total amount of scientific and technological credit in all the 
credit scale is very low. 2011 and the end of 2012, science and technology loans were $\$ 0.24 \%$, respectively, accounting for and $0.27 \%$ of the total loan balance of the year, respectively.

On the other hand, the lack of scientific and technological financial franchise institutions. In January 2009 so far, science and technology branch of the pilot practice show that branch of science and technology as the scientific and technological resources and bank capital effective docking carrier is innovative development of science and technology of credit institutions, has become effective complement to the policy banks and state-owned commercial bank credit support, can enhance ease the financing problem of small and medium-sized enterprises of science and technology, effectively expanding financing channels for enterprises of science and technology. 2.direct financing of science and Technology Enterprises Limited

In the stock market financing, Inner Mongolia in the SME board and the GEM listed companies less number, a limited amount of financing, as of the end of 2013, Inner Mongolia in the SME board only two listed companies and IPO Financing totaled 12.54 billion yuan; in the gem has three listed companies, IPO Financing totaled only 1.128 billion yuan. In the bond market, is still in support of large enterprises, small and medium enterprises through the bond market financing is strictly limited.2013, the region's only 8 companies to issue private debt, the total amount of the from play, the autonomous region of small and medium-sized scientific and technological enterprises through the property rights trading center for equity transactions and the number of intellectual property transactions is still less.In the aspect of venture capital market, compared with the national level, the development of venture investment in Inner Mongolia is still very backward, the specific performance of the late start and slow development, small number, small scale of capital.

2.science and technology financial services system is not perfect, the credit guarantee mechanism is not perfect

Information resources sharing platform construction lag. At present, in Inner Mongolia in the financial system, and between the functions of the government compartmentalization, fragmented, information blocking is more common, between government departments cooperation and on the linkage is not enough;Guarantee system is not perfect, the guarantee mechanism is not smooth. On the one hand, the development of security institutions lag. On the other hand, science and technology guarantee mechanism is not perfect.

Three, draw lessons from the domestic experience, promote the Inner Mongolia science and technology finance development strategy suggestion

(a) local government should raise awareness and increase support for the work of science and Technology Finance

First of all, autonomous governments at all levels and the relevant regulatory authorities should attaches great importance to science and technology finance with the strategic significance of the work, effective implementation of financial technology existing policy documents spirit, draw lessons from the advanced experience of other provinces

Secondly, continue to increase the local government public investment in science and technology, innovative financial investment in science and technology, give full play to the the guiding role of financial funds

Finally, strengthen the construction of venture capital fund. Encourage and support the autonomous region of science and technology departments, science and technology parks set up venture capital fund to promote venture capital investment and scientific and technological project effective docking.

(b) to vigorously promote the development of bank credit, improve the efficiency of financial resources allocation

Actively increase credit support for scientific and technological innovation. On the one hand, continue to increase input in policy bank credit, and actively explore new mode of credit \& Inner Mongolia can draw lessons from the Sichuan Branch of China Development Bank System by the system "mode, the relevant government departments to provide service platform, financial support and risk compensation, by venture capital as a financing platform, the bank provides credit funds, guarantee organization credit enhancement, through multilateral cooperation, achieve mutual 
benefit and win-win..

(c) to make full use of the multi-level capital market system, to effectively support the development of scientific and technological enterprises

Actively promoting science and technology enterprises through the stock market financing, first of all, increase scientific and technological enterprises listed resource library construction, Secondly, to make full use of the National SME share transfer system (that is, three new board) expansion opportunities to accelerate the cultivation of more start-up and growth period of scientific and technological enterprises.Also, should accelerate the development of local bond markets, continue to steadily promote the development of corporate bonds, corporate bonds, short-term financing bonds and medium-term notes, for the expansion of the small and medium-sized enterprise set bond issuance, actively explore in line with enterprise of science and technology characteristics of new varieties of bonds, the establishment of service to enterprise of science and technology, the flexible financing mechanism.

(d) actively promote the development of science and technology insurance and guarantee the development of science and technology, improve the risk sharing and compensation mechanism

Actively promoting the science and technology insurance services, the establishment of science and technology insurance service mechanism. We should strengthen the propaganda of science and technology insurance. Low cognitive science and technology insurance rate is an important factor to restrict the development of science and technology insurance, at present many technology companies are the real meaning of science and technology insurance and the specific scope of protection is not very understanding and need to local government and insurance companies together to increase publicity efforts, actively carry out of Science and technology insurance insurance related personnel

Actively promoting the development of science and technology guarantee business, the establishment of risk compensation mechanism. Actively develop various forms of security companies, through government funded in full dedicated to the service of science and technology enterprises policy guarantee mechanism, can draw lessons from the practice of SME credit guarantee company in Chengdu, year by year increase the registered capital, continued to enlarge the guarantee ability;At the same time, the use the leverage of the government guarantee fund, to encourage private capital to enter the security market, set up commercial guarantee institutions, as soon as possible to establish SME credit guarantee institutions, strengthen the guarantee mechanism to resist risks, eliminate hidden dangers of banks and other financial institutions, financing service cooperation will increase.

(e) to build a scientific and technical financial information service platform, to optimize the ecological environment of Regional Technology

Financial technology in the information asymmetry between subjects are science and technology enterprise financing is one of the important reasons leading to, to effectively solve this problem, need to join the parties work together to build financial technology integrated information service platform. Specific practices can lead by the local government, relying on around the Productivity Promotion Center, science and technology business incubator and venture capital institutions, combined with all kinds of financial intermediary, industry associations, credit institutions, property rights trading center, work together to build a science and technology financial information service platform system, establish various forms of financial services technology platform, including such as government information public platform, science and technology and financial services companies, venture investment service center, scientific and technological achievements transformation centers, science and technology enterprise investment and financing of public service platform and so on.

\section{Reference}

[1] Deng Tianzuo Zhang Junfang, a few of China's financial development in science and technology on [J] securities market Herald, 2012, (12). 
[2] Li Xingwei of Zhongguancun science and technology financial innovation problems and Countermeasures of [J] securities market Herald, 2011, (1).

[3] leaves Zijing, science and technology finance "mode of Hangzhou" 6 key points of [J] science and technology today, 2013, (2).

[4] Wu Xianman, etc., Jiangsu Science and technology development and innovation of financial research [J]. Southeast University Journal (PHILOSOPHY AND SOCIAL SCIENCES EDITION), 2012, (9),

[5] Jiang Shiyin, speed up the financial service system of science and technology building, Chengdu experience, problems and countermeasures [J], southwest finance, 2012, (5),

[6] Wuhan branch of the people's Bank of China business management department of monetary and credit statistics research group, Wuhan science and technology finance model: the status of the review, the typical model and improve the strategy of [J], Wuhan finance, 2013, (2). 